\title{
Linkage Between Microstructure and Chemical Composition of Iron-Rich Hard Dental Tissues From the Feral Coypu by Analytical TEM Investigations
}

\author{
Vesna Srot ${ }^{1}$, Ute Salzberger ${ }^{1}$, Birgit Bussmann ${ }^{1}$, Boštjan Pokorny ${ }^{2}$, Ida Jelenko ${ }^{2}$ and Peter A. van Aken ${ }^{1}$ \\ 1. Stuttgart Center for Electron Microscopy, Max Planck Institute for Intelligent Systems, Stuttgart, \\ Germany \\ 2. Ecological Research and Industrial Cooperation, Velenje, Slovenia
}

A great diversity of biominerals possessing a variety of structures can be produced by living organisms. Many of these biominerals are complex composite materials with excellent physical and mechanical properties [1,2] which cannot be formed man-made. The unique combinations of organic matrix and crystalline or amorphous minerals linked together and formed under particular conditions possess masterpiece architectures which leads to superior materials characteristics compared to their inorganically formed mineralogical varieties [2,3].

Rodents possess opposing long pairs of incisors that continuously grow through their lives, since they wore down by gnawing. The front surface of the incisors is enamel, which is the hardest tissue of the body consisting of $96 \mathrm{wt} \%$ of inorganic material; the inner surface represents softer dentine that forms the bulk of the teeth [4]. The characteristic orange-brown colour of the surface of incisors of different rodent species is identified with the presence of iron [5]. A report on the characterization of the surface layer of enamel from rat incisors by using electron microprobe analysis [6] demonstrated that the amount of iron $(\mathrm{Fe})$ is $10-30 \mathrm{wt} \%$.

In this study, incisors of the feral coypu (Myocastor coypus Molina) were investigated. The microstructure and the chemical composition at the enamel surface were studied in detail by using energy-dispersive X-ray spectroscopy (XEDS) and electron energy-loss spectroscopy (EELS) combined with scanning transmission electron microscopy (STEM) imaging at high spatial resolution using a VG HB501UX microscope.

Our preliminary investigations revealed the layer with a thickness of around $0.4 \mu \mathrm{m}$ (Fe-SL in Figure 1) present on the top of Fe-rich enamel (Fe-E in Figure 1) that has not been reported in the present literature. Annular dark field (ADF)-STEM images of the cross-sectional view showing the interface between the Fe-rich surface layer (Fe-SL) and the Fe-rich enamel (Fe-E) are presented in Figure 1. According to our XEDS measurements (not shown here) the amount of Fe present in this layer (Fe-SL) is much higher compared to the concentration levels for hard dental tissues in rodents reported by now. In addition, we observed lines of different thicknesses (10-20 nm) within the Fe-rich layer (Fe-SL in Figure 1), where minor variations in the elemental composition were detected by XEDS. O-K and Fe$\mathrm{L}_{2,3}$ energy-loss near-edge structures (ELNES) acquired from the mentioned layer are shown in Figure 2. The Fe- $\mathrm{L}_{2,3}$ edges (Figure $2 \mathrm{~b}$ ) exhibit two main spin-orbit split $\mathrm{L}_{3}$ and $\mathrm{L}_{2}$ peaks exhibiting characteristics of the Fe valence state [7,8]. Based on ELNES fingerprinting we can conclude that $\mathrm{Fe}$ in the Fe-rich layer (Fe-SL) is predominantly in $\mathrm{Fe}^{3+}$ state. In the course of our work a detailed chemical composition of enamel at different positions to the Fe-rich layer were studied and the corresponding $\mathrm{Ca} / \mathrm{P}$ ratios were determined and will be discussed.

There is a wide occurrence of Fe in many organisms and present findings will help to improve the 
understanding of Fe incorporation in the hard dental tissues at the nanoscale level.

References:

[1] UGK Wegst and MF Ashby, Philos Mag 84 (2004), 2167.

[2] AP Jackson and JFV Vincent, J Mater Sci 25 (1990), 3173.

[3] PUP Gilbert et al., Rev Mineral Geochem 59 (2005), 157.

[4] BA Niemec in "Small animal dental, oral \& maxillofacial disease" (2010), Manson Publishing Ltd, London.

[5] EV Pindborg JJ Pindborg and CM Plum, Acta Pharmacol 2 (1946), 294.

[6] A Halse, Archs Oral Biol 19 (1974), 7.

[7] LAJ Garvie, AJ Craven and R Brydson, Amer Mineral 79 (1994), 411.

[8] PA van Aken, B Liebscher and VJ Styrsa, Phys Chem Minerals 25 (1998), 323.

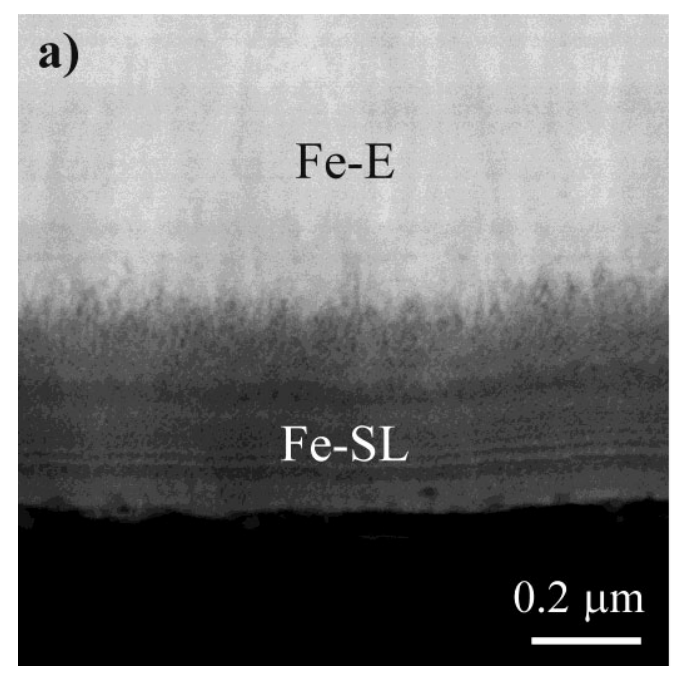

\section{b)}

Fe-E

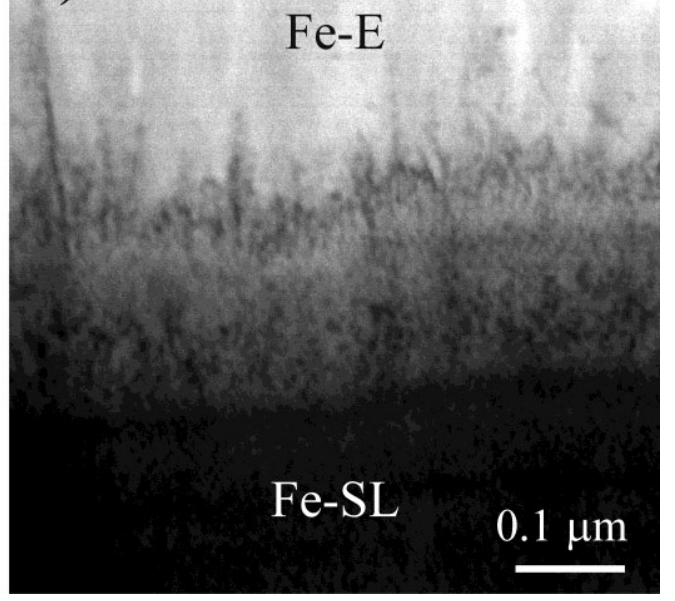

Figure 1. ADF-STEM images $(a, b)$ of the interface between the Fe-rich surface layer (Fe-SL) and the Fe-rich enamel (Fe-E).
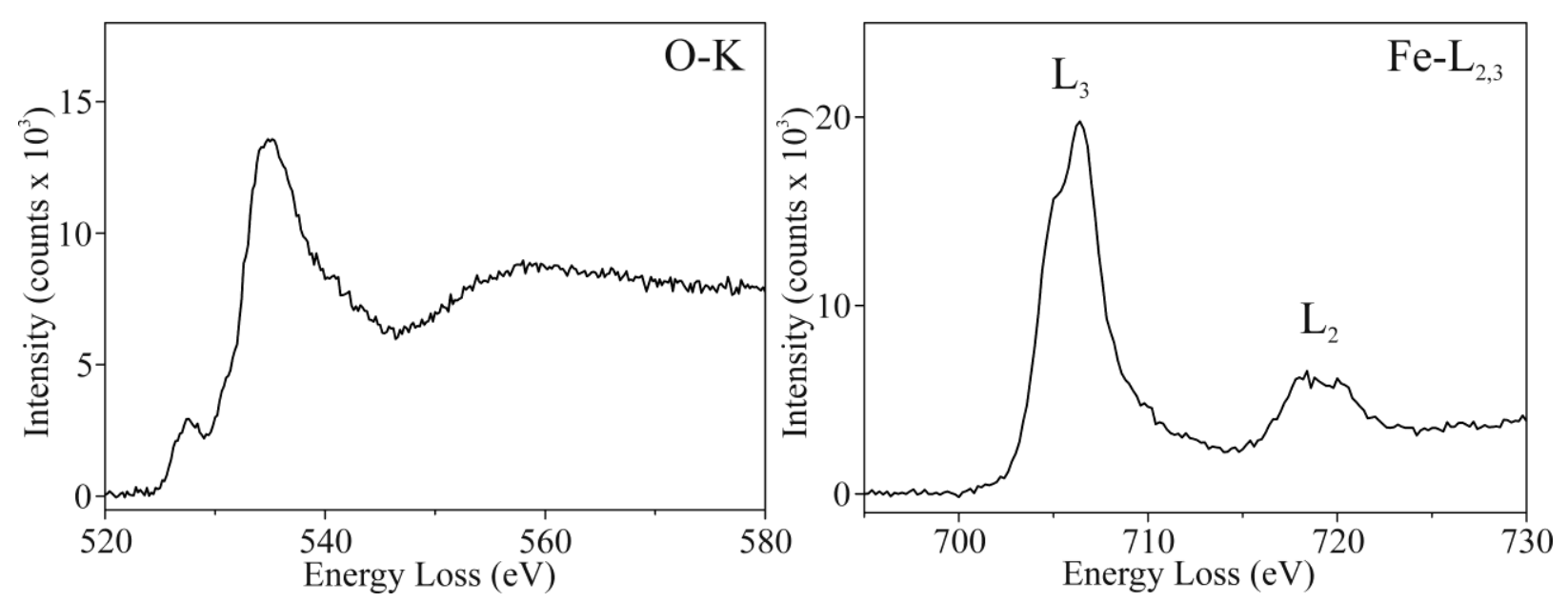

Figure 2. $\mathrm{O}-\mathrm{K}$ and $\mathrm{Fe}-\mathrm{L}_{2,3}$ ionization edges acquired from the $\mathrm{Fe}$-rich surface layer (Fe-SL). 